ON THE RECORD

csome never make a pregnancy, some die before term, some die of disease, some live but are large. And some are just fine those are the real mysteries.)

Reproductive biologist Mark Westhusin describes the lottery of cloning. He brought the first cloned cat and deer into the world. The first cloned dog is reported on page 641.

\section{(CThis hair sample could not have come from the hairy bipedal animal that was reportedly sighted in Teslin last week.》”}

Geneticist David Coltman dashes hopes of proving Bigfoot's existence, after mitochondrial DNA from hair found near a suspected sighting produced a $100 \%$ match with bison sequences.

\section{SCORECARD}

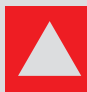
Room to think Between 2001 and 2003, the floor space dedicated to scientific research at US colleges and universities rose $11 \%$ to 16 million square metres, making it a real growth area.

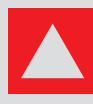
Remains of the day Fossil hunters could soon get a chance to seek signs of life on Mars. NUGGET, an instrument proposed by NASA, would use neutron beams to peer inside rocks and draw threedimensional images of any remains within.

\section{NUMBER CRUNCH} NASA TV is taking over the world...

50,000 The peak number of simultaneous webcast streams sent out by NASA for the Mars Rover landings in January 2004.

118,000 The peak number of streams sent out for the Deep Impact mission on 4 July 2005.

433,000 The peak number of streams sent out for the space shuttle launch on 26 July 2005.

Source: NASA

\title{
Shadow hangs over research into Japan's bomb victims
}

On 6 and 9 August 1945, nuclear bombs dropped by the United States flattened the Japanese cities of Hiroshima and Nagasaki. The explosions killed 120,000 people; at least twice as many have since died from the effects of being exposed to radiation.

The attacks changed the political landscape for ever, but they have also made a major impact on science. The Radiation Effects Research Foundation (RERF) laboratories in Hiroshima and Nagasaki have tracked more than 80,000 survivors of the bombings, and the knowledge gained now forms the basis of our understanding of how radiation causes cancer, as well as the radiation protection standards used in hospitals and nuclear facilities. Yet 60 years on, uncertainties over US funding, and the foundation's ageing facilities, are causing fears about the future of a project that is still far from the end of its scientific life.

Over the past six decades, researchers at RERF have collected vast amounts of data from surveys, health examinations and biological samples, providing a resource for epidemiologists around the world. The survivors were a normal slice of the Japanese population. And unlike subsequent disasters such as Chernobyl, where some of the exposure came later through environmental contamination, almost all the radiation was delivered when the bomb detonated, making it easier to estimate each person's dose.

"We are talking about the biggest epidemiological study ever conducted," says Yuri Dubrova, an expert on the effects of radiation on the human germline at the University of Leicester, UK. "The data from RERF produced information that is still the gold standard in terms of cancer studies. This is ongoing and astoundingly important research.”

Charles Land of the US National Cancer Institute in Bethesda, Maryland, says that with some $45 \%$ of survivors still alive, the most useful information may be yet to come. "There's still a lot to learn," he says. "As the exposed population ages, there is going to be a lot more information coming from the survivors."

Studies over the past decade or so are also starting to suggest that exposure to radiation increases the risk of many diseases besides cancer, and that there may be no safe dose for treatments such as radiotherapy (see 'Fallout beyond cancer', below).

But despite the project's value, many experts are worried about its future. The foundation's budget has been around $¥ 3.8$ billion (US $\$ 33.8$ million) for several years. Until 1996, half of that came from the United States, but its contribution has dropped to $38 \%$.

Then last year, the US Department of Energy (DoE) suggested cutting its annual contribu-
tion. Full funding was evention. Fully delivered four months late and is guaranteed for another two years, but some are edgy that a similar situation could arise again. "Let's hope the DoE doesn't try any more of the tricks it did last year," says Mark Little, an epidemiologist at Imperial College London. "It's vital they keep going for the foreseeable future."

Little has worked with data from RERF for the past 15 years, and was lead author of a letter sent to The Lancet last year in protest at the proposed budget cuts (M. P. Little et al. Lancet $364,557-558 ; 2004)$. He says that the foundation's facilities in Hiroshima, housed in prefabricated huts built in 1949, are run down. Roofs leak and leaves blow into labs. There are also staffing problems. "There have been significant departures of epidemiologists," says Little. “They are struggling

\section{Fallout beyond cancer}

Over the past decade, it has become clear that those who witnessed the Hiroshima and Nagasaki bombings do not just face an increased cancer risk. They also have higher rates of high blood pressure, stroke, and liver and kidney problems, among others.

When first identified in the early 1990s, some doubted that these effects were real, as there was no obvious way for radiation to cause such diseases. But more data have

strengthened the evidence and the effects are now widely accepted. Around 4,500 survivors have died of heart disease since the bombs, for example, and 100 of these are associated with the radiation.

"We've been discovering what in the past would have been unthinkable as damage from radiation exposure," says Kazuo Neriishi, who 


\section{IMAGE}

UNAVAILABLE

FOR COPYRIGHT

REASONS

Out of the ashes: survivors of Hiroshima and Nagasaki form 'the biggest epidemiological study ever'.

to do the analysis on the latest samples."

Dale Preston, an epidemiologist formerly at RERF, shares Little's concerns. "Over the past few years people have been less keen to work in this area," he says. "But there's nothing that can do the kind of work RERF can do."

Kazunori Kodama, chief scientist at RERF, says that work is continuing for the time being. "The place is holding out right now," he says. "But I'm still worried about what will happen after 2007."

Tom Simonite

Additional reporting by Jim Giles in London, and Ichiko Fuyuno and David Cyranoski in Tokyo studies cataract risks at the Radiation Effects Research Foundation in Hiroshima.

Some researchers are now asking what the bomb data might reveal about the risk to radiotherapy patients. Comparing the groups is complex, as the survivors received a dose across their bodies. In radiotherapy, the radiation is focused on the tumour. But some epidemiologists believe that there is enough evidence to warrant further studies.

Sarah Darby, an epidemiologist at the University of Oxford, UK, says that the relationship between radiation dose and heart disease for the survivors follows a smooth curve. This shows that there may be no cut-off point, with even low doses affecting disease rates.

In a study published online last month, Darby and her colleagues show that British women who had received radiotherapy for cancer in their left breast, the side on which the heart is located, were up to $50 \%$ more likely to die of heart disease than those whose right breast was treated (S. C. Darby et al. Lancet Oncol. 6, 557-565; 2005).

Darby says radiotherapy doses have since been reduced in the United Kingdom, but she believes the bomb data show that patients may still be at risk. She is trying to investigate this through further studies of radiotherapy patients.

Researchers say they are some way from being able to confirm the mechanism behind the increased heart-disease rates. Some suspect that it may lie in a chain of physiological changes set off by the immune system's response to the initial radiation dose. 